Article

\title{
Kinetically Limited Phase Formation of Pt-Ir Based Compositionally Complex Thin Films
}

\author{
Aparna Saksena ${ }^{1, *}$, Dimitri Bogdanovski ${ }^{1}{ }^{(\mathbb{C}}$, Hrushikesh Sahasrabuddhe ${ }^{2}$, Denis Music ${ }^{1}(\mathbb{D}$ and \\ Jochen M. Schneider ${ }^{1}$ \\ 1 Materials Chemistry, RWTH Aachen University, 52056 Aachen, Germany; \\ bogdanovski@mch.rwth-aachen.de (D.B.); music@mch.rwth-aachen.de (D.M.); \\ schneider@mch.rwth-aachen.de (J.M.S.) \\ 2 Department of Metallurgical and Material Science, Indian Institute of Technology, Bombay, \\ Mumbai 400076, India; hrushikesh_sahasrabuddhe@iitb.ac.in \\ * Correspondence: saksena@mch.rwth-aachen.de
}

Received: 17 April 2020; Accepted: 14 May 2020; Published: 16 May 2020

check for updates

\begin{abstract}
The phase formation of $\operatorname{PtIrCuAuX~}(X=\mathrm{Ag}, \mathrm{Pd})$ compositionally complex thin films is investigated to critically appraise the criteria employed to predict the formation of high entropy alloys. The formation of a single-phase high entropy alloy is predicted if the following requirements are fulfilled: $12 \mathrm{~J} \cdot \mathrm{K}^{-1} \mathrm{~mol}^{-1} \leq$ configurational entropy $\leq 17.5 \mathrm{~J} \cdot \mathrm{K}^{-1} \mathrm{~mol}^{-1},-10 \mathrm{~kJ} \cdot \mathrm{mol}^{-1} \leq$ enthalpy of mixing $\leq 5 \mathrm{~kJ} \cdot \mathrm{mol}^{-1}$ and atomic size difference $\leq 5 \%$. Equiatomic PtIrCuAuX $(X=\mathrm{Ag}$, Pd) fulfill all of these requirements. Based on $\mathrm{X}$-ray diffraction and energy-dispersive $\mathrm{X}$-ray spectroscopy data, near-equiatomic $\mathrm{Pt}_{22} \mathrm{Ir}_{23} \mathrm{Cu}_{18} \mathrm{Au}_{18} \mathrm{Pd}_{19}$ thin films form a single-phase solid solution while near-equiatomic $\mathrm{Pt}_{22} \mathrm{Ir}_{23} \mathrm{Cu}_{20} \mathrm{Au}_{17} \mathrm{Ag}_{18}$ thin films exhibit the formation of two phases. The latter observation is clearly in conflict with the design rules for high entropy alloys. However, the observed phase formation can be rationalized by considering bond strengths and differences in activation energy barriers for surface diffusion. Integrated crystal orbital Hamilton population values per bond imply a decrease in bond strength for all the interactions when Pd is substituted by $\mathrm{Ag}$ in PtIrCuAuX which lowers the surface diffusion activation energy barrier by $35 \%$ on average for each constituent. This enables the surface diffusion-mediated formation of two phases, one rich in $\mathrm{Au}$ and $\mathrm{Ag}$ and a second phase enriched in $\mathrm{Pt}$ and $\mathrm{Cu}$. Hence, phase formation in these systems appears to be governed by the complex interplay between energetics and kinetic limitations rather than by configurational entropy.
\end{abstract}

Keywords: phase formation; high entropy alloy (HEA); compositionally complex alloys; HEA design criteria; activation energy for surface diffusion

\section{Introduction}

Platinum and its alloys are known for their spectacular performance in most corroding environments at elevated temperatures [1,2]. These materials are extensively used in applications demanding corrosion resistance $[1,3]$ as well as high strength such as organic chemical synthesis $[4,5]$, electrode materials in fuel cells [6,7], implantable medical devices [8,9] or precision glass molding [10-13]. While addition of Au to Pt-based alloys improves the high-temperature corrosion resistance [2], Ir additions enhance the stiffness [1,3]. Elemental Ir is known for its high elastic modulus of $525 \mathrm{GPa}$ which is comparable to some of the existing ceramics in use [3].

As for noble metal senary systems, Sohn et al. [14] investigated the phase formation of two compositions with identical configurational entropies, namely PtPdRhIrCuNi and AuPdAgPtCuNi, by casting. While PtPdRhIrCuNi formed a single-phase, AuPdAgPtCuNi formed a two-phase 
mixture [14]. The authors attribute the formation of the second phase to energetics, namely the large pairwise enthalpy of mixing [14].

Enhanced properties are one of the key motivations for research on high entropy alloys (HEA) and compositionally complex alloys (CCA) [15]. Miracle and Senkov [16] stated that "HEAs have been tightly associated with finding single-phase solid solutions by controlling configurational entropy". Furthermore, and in line with a proposal by Miracle and Senkov [16], we refer to multi-principal element alloys forming multiphase microstructures as complex concentrated alloys (CCAs). Contrary to the conventional alloys, HEAs are defined to contain five to 13 major constituting elements where the concentration of each element ranges from 5 to 35 at.\% [17]. According to Zhang et al., the formation of HEAs is predicted for materials exhibiting $12 \mathrm{~J} \mathrm{~K}^{-1} \cdot \mathrm{mol}^{-1}(\approx 1.44 \cdot R) \leq$ configurational entropies $\leq 17.5 \mathrm{~J} \cdot \mathrm{K}^{-1} \mathrm{~mol}^{-1}(\approx 2.10 R),-10 \mathrm{~kJ} \cdot \mathrm{mol}^{-1} \leq$ enthalpies of mixing $\leq 5 \mathrm{~kJ} \cdot \mathrm{mol}^{-1}$ and atomic size differences $\leq 5 \%$ [18], with $R$ as the gas constant $\left(\approx 8.3144 \mathrm{~J} \mathrm{~K}^{-1} \cdot \mathrm{mol}^{-1}\right)$. However, over time, these guidelines were revealed not to be entirely successful at predicting the formation of single-phase solid solutions [14,19-22].

While the role of kinetics associated with the synthesis process and its effect on the phase formation has not been investigated for noble metal multi-principal element alloys, a phase formation study on $\mathrm{Pt}-\mathrm{X}(\mathrm{X}=\mathrm{Ir}, \mathrm{Au})$ elucidates the role of kinetics during vapor phase condensation [23]. Pt-Ir formed a single metastable fcc phase, while Pt-Au formed two fcc phases. This was attributed to the activation energy for surface diffusion, which is up to six times higher for Ir on a Pt-Ir surface compared to Au on a Pt-Au surface [23].

In the present investigation, the above discussed HEA design criteria [18] are critically appraised for the phase formation of PtIrCuAuX (X = Ag, Pd) thin films. Specifically, the influence of activation energy barriers for surface diffusion on the phase formation is investigated.

\section{Experimental and Theoretical Methods}

\subsection{Experimental Methods}

A schematic representation of the combinatorial magnetron sputtering setup is presented in previous studies $[23,24]$. During sputtering the cooling rate was estimated to be $>10^{10} \mathrm{~K} \mathrm{~s}^{-1}$, reaching $10^{15} \mathrm{~K} \cdot \mathrm{s}^{-1}$, by Barbee et al. [25]. PtIrCuAuAg thin films were synthesized at substrate temperatures of $520^{\circ} \mathrm{C}$, while PtIrCuAuPd thin films were additionally deposited at $800^{\circ} \mathrm{C}$. All growth experiments were carried out by direct current (DC) magnetron sputtering in an Ar atmosphere at a pressure of $0.4 \mathrm{~Pa}$. The base pressure before deposition was $\leq 7 \times 10^{-5} \mathrm{~Pa}$. For the quinary material system, an $\mathrm{Au}-\mathrm{Cu}$ alloy target (50 at.\% each, $99.9 \%$ purity) was employed together with the elemental targets of $\mathrm{Pt}(99.99 \%$ purity), Ir (99.9\% purity), $\mathrm{Ag}$ (99.99\% purity) (in the case of $\mathrm{PtIrCuAuAg}$ ) and $\mathrm{Pd}$ (99\% purity) (in the case of PtIrCuAuPd). The average applied power densities were $3.6 \mathrm{~W} \cdot \mathrm{cm}^{-2}$ for Ir and $2.3 \mathrm{~W} \cdot \mathrm{cm}^{-2}$ for $\mathrm{Pt}$, while for Au-Cu alloy target and $\mathrm{Ag}$ the power densities were varied between 1.0 and $2.5 \mathrm{~W} \cdot \mathrm{cm}^{-2}$ to enable the synthesis of quinary PtIrCuAuAg thin films. For the PtIrCuAuPd thin film depositions, the average power densities were $3.6 \mathrm{~W} \cdot \mathrm{cm}^{-2}$ for Ir and $2.3 \mathrm{~W} \cdot \mathrm{cm}^{-2} \mathrm{for} P \mathrm{P}$, while the $\mathrm{Au}-\mathrm{Cu}$ alloy target and $\mathrm{Pd}$ were subjected to 3.6 and $1.0 \mathrm{~W} \cdot \mathrm{cm}^{-2}$, respectively. The substrate-to-target distance was $10 \mathrm{~cm}$ for all growth experiments, whereby $\mathrm{Al}_{2} \mathrm{O}_{3}(0001)$ single crystal substrates were used without substrate rotation.

The composition gradients were analyzed by energy-dispersive X-ray spectroscopy (EDS) using a JEOL JSM-6480 scanning electron microscope (JEOL Ltd., Tokyo, Japan), equipped with an EDAX Genesis 2000 detector (EDAX Inc./Ametek MAD, Mahwah, NJ, USA). The elemental compositions were determined by ZAF corrections [26] utilizing the measured characteristic $X$-ray intensities of the $\mathrm{L}$ lines for $\mathrm{Pt}, \mathrm{Ir}, \mathrm{Au} \mathrm{Ag}$ and $\mathrm{Pd}$, and the $\mathrm{K}$ line for $\mathrm{Cu}$. The acceleration voltage was $15 \mathrm{keV}$.

Atom probe tomography (APT) was used to elucidate the spatially resolved composition via local electrode atom probe (LEAP 4000X HR $^{\mathrm{TM}}$ Cameca Instrument, Ametek MAD, Mahwah, NJ, USA). The laser-assisted field evaporation measurements were performed at $-213{ }^{\circ} \mathrm{C}$ with a laser energy of 
$80 \mathrm{pJ}$ and a frequency of $125 \mathrm{kHz}$. The IVAS 3.8 .0 software package was used for data reconstruction and analysis.

Structure analysis of the as-deposited thin films was performed using X-ray diffraction (XRD). A Bruker D8 general area detection diffraction system (GADDS, Bruker, Billerica, MA., USA) in grazing incidence geometry was employed to perform $2 \theta$ scans at a grazing angle of $10^{\circ}$, with $\mathrm{Cu} \mathrm{K} \alpha$ $(\lambda=1.5406 \AA)$ radiation. The generator voltage and current were set to $40 \mathrm{kV}$ and $40 \mathrm{~mA}$, respectively.

\subsection{Theoretical Methods: Ab Initio Calculations}

For PtIrCuAuX $(X=A g, P d)$, first-principles calculations based on density-functional theory (DFT) were performed employing the Vienna Ab Initio Simulation Package (VASP, version 5.4.4, Universität Wien, Vienna, Austria) [27,28]. The projector-augmented wave (PAW) method [29] was used for basis set representation within the framework of the generalized gradient approximation (GGA) with the established functional by Perdew, Burke and Ernzerhof (PBE) to account for exchange and correlation $[30,31]$. The plane-wave cut off energy and the energetic convergence criterion were set to be 500 and $10^{-6} \mathrm{eV}$, respectively. The Brillouin zone integration was performed via Blöchl's tetrahedron method for plane-wave basis sets [32], utilizing an appropriate $k$-points grid of $3 \times 3 \times 1$, chosen to ensure energetic convergence and generated via the Monkhorst-Pack approach [33]. As the system in question is not magnetically active, spin polarization was not considered in the calculations. The structures were fully relaxed in terms of cell volume and atomic positions. The total ground state energy of the equilibrium structure was obtained from an additional static calculation.

The energy of formation of the quinary systems was calculated with the 108-atom special quasi-random structures (SQS) [34]. The Warren-Cowley short-range order parameter [35] was within 0.1 for 8 coordination shells. The average volume of the relaxed SQS cell was used to obtain the lattice constants of different configurations of $\operatorname{PtIrCuAuX}(X=\mathrm{Ag}$, Pd) by fitting the total energy as a function of cell volume using the Birch-Murnaghan equation of state [36].

The activation energy barrier for surface diffusion was estimated according to Chang et al. [34], by moving an atom stepwise from its equilibrium lattice site to the nearest neighboring site in the close-packed plane (111) along the $<110>$ direction. The movement of the atom occurs within the surface layer (no adatom motion) to a neighboring vacancy to mimic the sputtering process. This method has been used to investigate the influence of surface diffusion on the phase formation of $\mathrm{Cu}-\mathrm{W}$ [34,37], $\mathrm{Cu}-\mathrm{V}$ [37], Pt-X (X = Ir, Au) [23] and TiAlN [38] thin films. The activation energy barrier was determined by the difference of the maximum (saddle point) and minimum (equilibrium) energies along this path. These calculations were carried out for a 180-atom supercell whose energy per atom is closest to that of an SQS cell with identical composition. The thickness of the vacuum layer was $10 \AA$. It should be stressed that, firstly, all these calculations were performed for the movement of an atom to a neighboring site which may or may not be the respective global minimum for a given system, and secondly, that the activation energy barrier of surface diffusion can also depend on the environment of the moving atom.

Bonding interaction analyses were performed utilizing the crystal orbital Hamilton population (COHP) method, with local orbitals projected from delocalized plane-wave basis sets $[39,40]$ as implemented in the LOBSTER package (version 3.2.0, Chair of Solid State Chemistry, Institute of Inorganic Chemistry, RWTH Aachen University, Aachen, Germany) [41,42]. Two structural models of a slightly Pt/Ir-enriched 108-atom configuration, $\mathrm{Pt}_{23} \mathrm{Ir}_{23} \mathrm{Cu}_{21} \mathrm{Au}_{21} \mathrm{X}_{20}(\mathrm{X}=\mathrm{Ag}$, $\mathrm{Pd})$, as generated via the SQS approach described above, with identical atomic arrangement and solely differing in the atomic species of $X$, were used in order to isolate the sole effect of atomic substitution on bonding. After full relaxation of these two systems, the generated plane-wave wave functions were projected onto local atomic orbitals to enable the quantification of the integrated COHP (ICOHP) values at the Fermi level for all possible atom pair interactions within the first three coordination shells (CS) of a given atom. These ICOHP values serve as an indirect but strongly correlated, and thus reliable, descriptor of the respective bond strength; however, by nature of the method, covalent bonding is assumed. 
Thus, in metallic systems with a high degree of electron delocalization, bonding characteristics are only partially described by the COHP approach. Nevertheless, trends are regularly reproduced well, and COHP analyses are routinely used for the qualitative description of bonding in metallic systems in literature [43-45].

\section{Results and Discussion}

According to Zhang et al. [18], the formation of a single-phase solid solution is predicted based on the following criteria: atomic size difference $(\partial(\%))$, enthalpy of mixing $\left(\Delta H_{\text {mix }}\right)$ and the configurational entropy $\left(\Delta S_{\text {mix }}\right)$ of the HEA. Specifically, for the formation of a single-phase HEA, the following criteria must be fulfilled: $-10 \mathrm{~kJ} \cdot \mathrm{mol}^{-1} \leq \Delta H_{\text {mix }} \leq 5 \mathrm{~kJ} \cdot \mathrm{mol}^{-1}[18], \partial \leq 5 \%$ [18] and $12 \mathrm{~J} \mathrm{~K}^{-1} \mathrm{~mol}^{-1}(\approx 1.44 \cdot R)$ $\leq \Delta S_{\text {mix }} \leq 17.5 \mathrm{~J} \cdot \mathrm{K}^{-1} \mathrm{~mol}^{-1}(\approx 2.10 \cdot R)$ [18]. These criteria are fulfilled for the $\mathrm{Pt}_{20} \mathrm{Ir}_{20} \mathrm{Cu}_{20} \mathrm{Au}_{20} \mathrm{X}_{20}$ and $\mathrm{Pt}_{27.5} \mathrm{Ir}_{27.5} \mathrm{Cu}_{15} \mathrm{Au}_{15} \mathrm{X}_{15}\left(\mathrm{X}=\mathrm{Ag}\right.$, Pd) compositions, whereas $\mathrm{Pt}_{35} \mathrm{Ir}_{35} \mathrm{Cu}_{10} \mathrm{Au}_{10} \mathrm{X}_{10}$ does not fulfill $12 \mathrm{~J} \cdot \mathrm{K}^{-1} \cdot \mathrm{mol}^{-1}(\approx 1.44 R) \leq \Delta S_{\text {mix }}$, as shown in Figure 1 . Hence, the formation of a single solid solution phase is predicted for $\mathrm{Pt}_{20} \mathrm{Ir}_{20} \mathrm{Cu}_{20} \mathrm{Au}_{20} \mathrm{X}_{20}$ and $\mathrm{Pt}_{27.5} \mathrm{Ir}_{27.5} \mathrm{Cu}_{15} \mathrm{Au}_{15} \mathrm{X}_{15}(\mathrm{X}=\mathrm{Ag}, \mathrm{Pd})$.

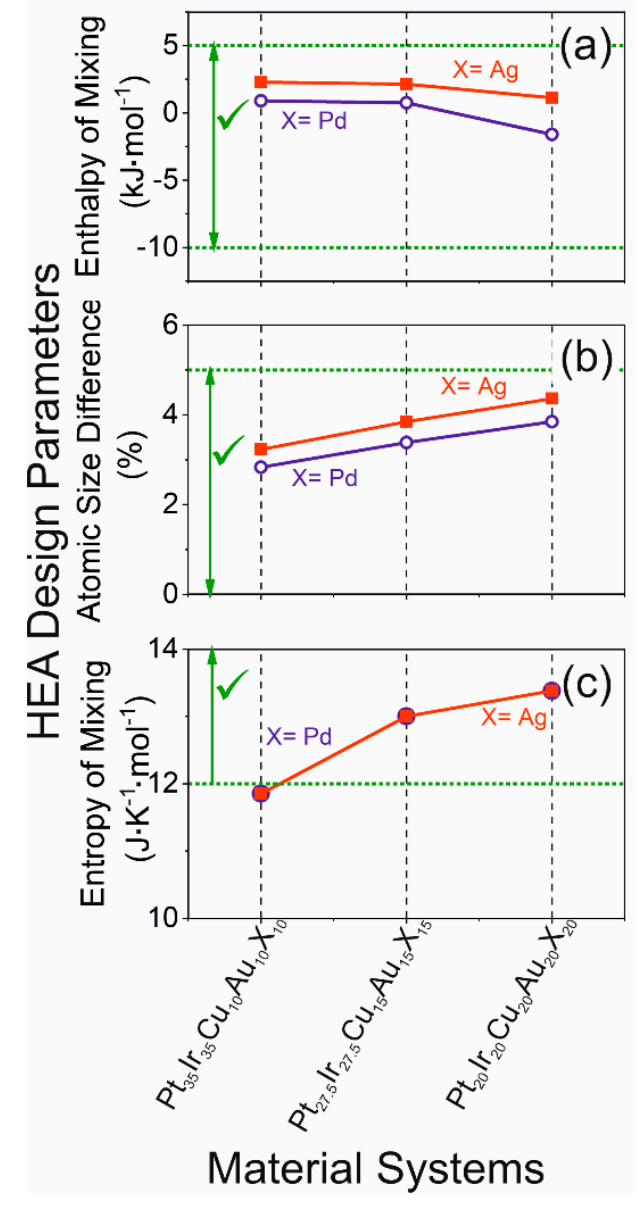

Figure 1. The enthalpy of mixing (a), the entropy of mixing (c), atomic size (b) difference for the different configurations of PtIrCuAuX $(X=A g$, Pd). The regions marked with " $\checkmark$ " fulfill the high entropy alloy (HEA) design criteria. The data points are connected to guide the eye.

Thin films with compositions similar to the above-discussed reference compositions were deposited. Figure 2a shows the XRD pattern of the near-equiatomic $\mathrm{Pt}_{22} \mathrm{Ir}_{23} \mathrm{Cu}_{20} \mathrm{Au}_{17} \mathrm{Ag}_{18}$ thin film, which, despite possessing a configurational entropy of $13.30 \mathrm{~J} \cdot \mathrm{K}^{-1} \cdot \mathrm{mol}^{-1}(\approx 1.60 \cdot R)$, clearly shows the formation of two distinct fcc phases where the lattice parameters of $\mathrm{FCC}_{1}$ and $\mathrm{FCC}_{2}$ are 3.83 and $4.03 \AA$, respectively. Hence, the observed phase formation is in conflict with the prediction discussed in the context of Figure 1. $\mathrm{Pt}_{27} \mathrm{Ir}_{29} \mathrm{Cu}_{15} \mathrm{Au}_{15} \mathrm{Ag}_{14}$, exhibiting a configurational entropy of $12.94 \mathrm{~J} \mathrm{~K}^{-1} \mathrm{~mol}^{-1}(\approx 1.55 \cdot R)$, 
also formed two fcc phases where, correspondingly, the lattice parameters of $\mathrm{FCC}_{1}$ and $\mathrm{FCC}_{2}$ are $3.83 \AA$ and $4.02 \AA$, respectively. However, as the $\mathrm{Ag}$, $\mathrm{Au}$ and $\mathrm{Cu}$ concentrations were reduced, the intensity of $\mathrm{FCC}_{2}$ weakens and the phase formation in $\mathrm{Pt}_{32} \mathrm{Ir}_{36} \mathrm{Cu}_{10} \mathrm{Au}_{12} \mathrm{Ag}$ 10, exhibiting a configurational entropy of $12.03 \mathrm{~J} \mathrm{~K}^{-1} \mathrm{~mol}^{-1}(\approx 1.45 \cdot R)$, is dominated by $\mathrm{FCC}_{1}$ with a lattice parameter of $3.83 \AA$, as observed by XRD, see Figure $2 a$. In Figure $2 b$, the diffractogram of a $\operatorname{Pt}_{22} \operatorname{Ir}_{23} \mathrm{Cu}_{18} \mathrm{Au}_{18} \mathrm{Pd}_{19}$ thin film deposited at $520{ }^{\circ} \mathrm{C}$ substrate temperature with a configuration entropy of $13.34 \mathrm{~J} \cdot \mathrm{K}^{-1} \cdot \mathrm{mol}^{-1}$ $(\approx 1.60 R$ ) clearly suggests the formation of a single fcc phase with a lattice parameter of $3.87 \AA$, in line with the above-discussed phase prediction guideline. However, the asymmetric (111) peak in the diffractogram of a film deposited at $800{ }^{\circ} \mathrm{C}$ substrate temperature, with an identical composition, clearly indicates the formation of a second phase absent at lower temperatures. If the phase formation were governed by configurational entropy, the more negative $T \mathrm{~d} S$ term should favor the formation of a single-phase. Hence, the phase formation observed herein is inconsistent with the predictions based on the aforementioned HEA design criteria.

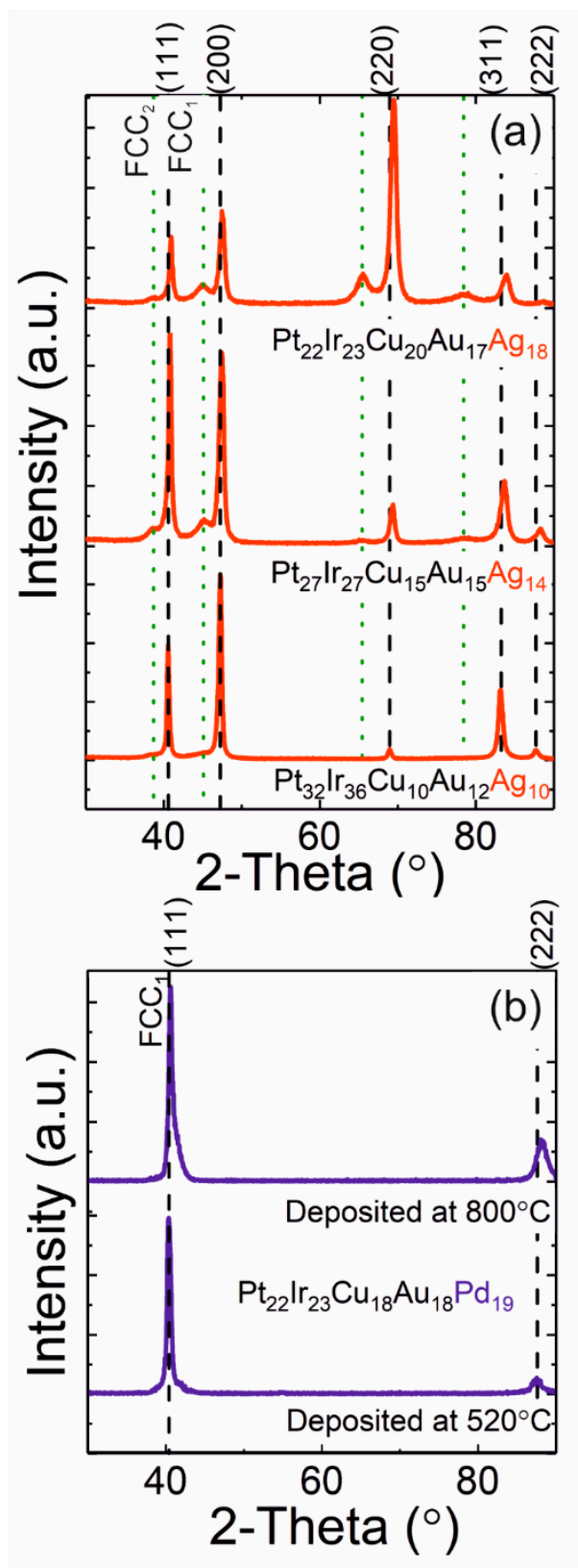

Figure 2. X-ray diffraction patterns depicting phase formation behavior of the PtIrCuAuAg (a) and PtIrCuAuPd (b) $(X=\mathrm{Ag}, \mathrm{Pd})$ material systems. FCC $_{2}$ designates a secondary fcc phase formation. 
To analyze the local chemical composition of the two phases, identified by XRD in the $\mathrm{Pt}_{22} \mathrm{Ir}_{23} \mathrm{Cu}_{20} \mathrm{Au}_{17} \mathrm{Ag}_{18}$ thin film deposited at $520{ }^{\circ} \mathrm{C}$, APT was performed. Figure 3 a shows the overall as well as the individual elemental distribution of the constituting species. It is evident that $\mathrm{Ag}$ and $\mathrm{Au}$ are not randomly distributed. In a frequency distribution analysis, a binomial or random distribution of the elements would result in a Pearson's coefficient ( $\mu$ ) equal to zero [46]. As shown in Figure $3 b$, all of the elements exhibit a non-random distribution. The calculated Pearson's coefficients for Pt $(\mu=0.96), \mathrm{Cu}(\mu=0.96), \mathrm{Au}(\mu=0.96)$, and Ag $(\mu=0.99)$ are consistent with clustering. The Pearson's coefficient of Ir $(\mu=0.86)$ suggests less clustering as compared to Pt, $\mathrm{Cu}, \mathrm{Au}$ and $\mathrm{Ag}$. A one-dimensional concentration profile for a cylindrical region of interest of $10 \times 10 \times 40 \mathrm{~nm}^{3}$ is compiled along the direction marked by the black arrow in Figure 3a and is shown in Figure 3c. From left to right, the analyzed region transitions from a phase, depleted in $\mathrm{Ag}$ and $\mathrm{Au}$, to the second phase, depleted in $\mathrm{Pt}$ and $\mathrm{Cu}$. The Ir concentration is similar in both phases. In the Pt-Cu rich phase, Au and Ag content are depleted by 12 and 15 at.\%, respectively, compared to the integral composition where $\mathrm{Pt}$ and $\mathrm{Cu}$ are both enriched by 15 at.\%. On the other hand, the Au-Ag rich region exhibits a depletion of both $\mathrm{Pt}$ and $\mathrm{Cu}$ by 8 at.\% each from the integral composition, as determined by APT.
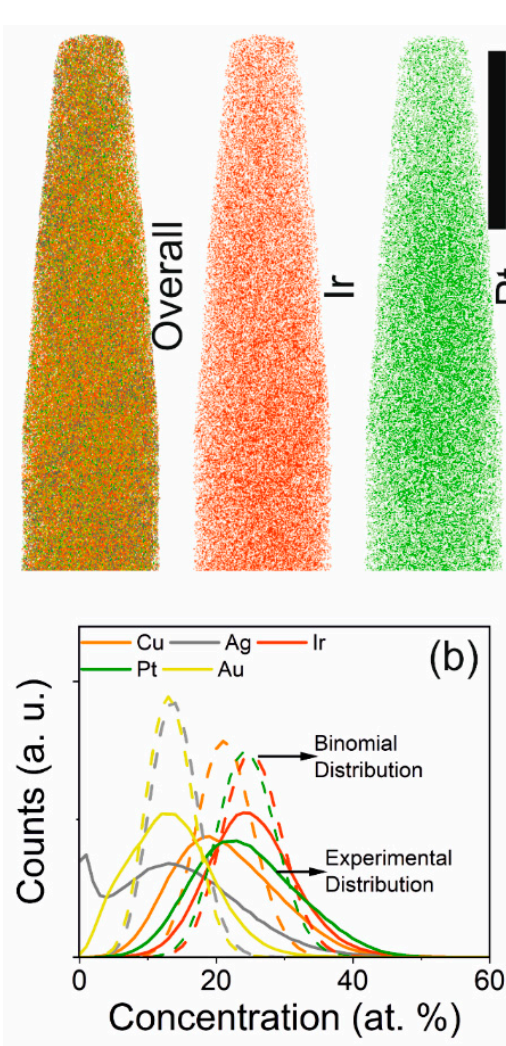
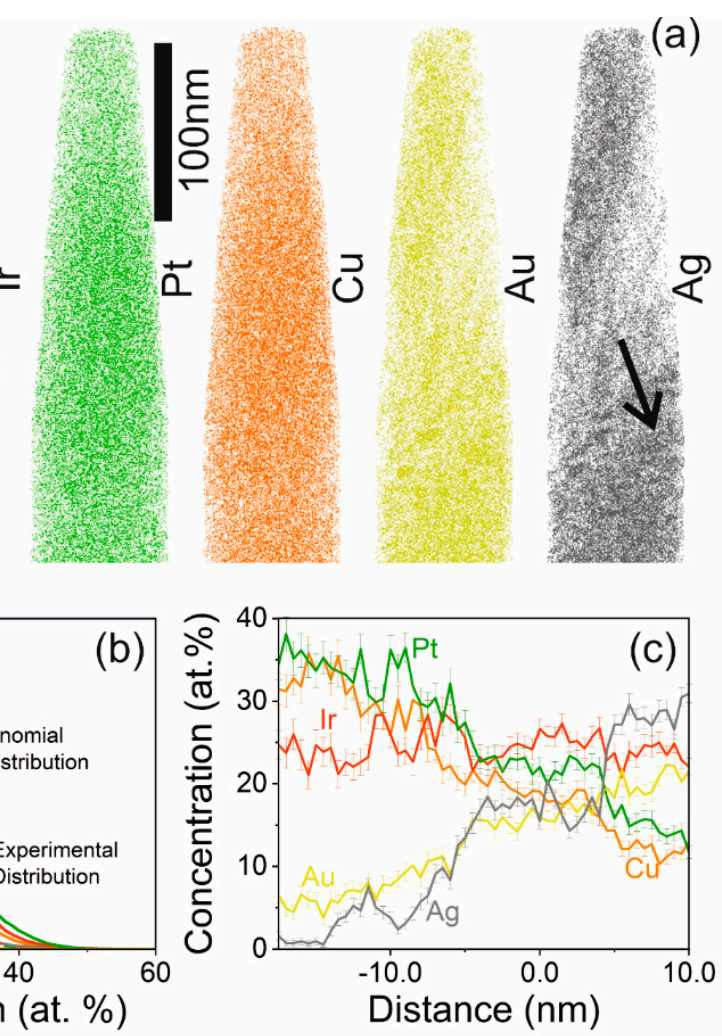

Figure 3. (a) Depiction of the overall as well as individual elemental distribution of $\mathrm{Pt}_{22} \mathrm{Ir}_{23} \mathrm{Cu}_{20} \mathrm{Au}_{17} \mathrm{Ag}_{18}$, via atom probe tomography. (b) Frequency distribution analysis of the constituting elements. (c) The one-dimensional concentration profile along the direction highlighted in (a), depicting the 2 phases: Au-Ag-depleted and -rich regions.

Figure $4 \mathrm{a}$ shows the overall as well as the individual elemental distribution of a $\mathrm{Pt}_{22} \mathrm{Ir}_{23} \mathrm{Cu}_{18} \mathrm{Au}_{18} \mathrm{Pd}_{19}$ thin film deposited at $520{ }^{\circ} \mathrm{C}$ substrate temperature, which according to XRD contains a single fcc phase. Although the overall elemental distribution appears quite homogeneous, chemical fluctuations are evident from the individual elemental distribution. The frequency distribution analysis is shown in Figure $4 \mathrm{~b}$. The Pearson coefficient of $\mathrm{Au}(\mu=0.71)$ indicates a non-random distribution. Even though $\mathrm{Pt}$ and $\mathrm{Ir}$ may appear to be more randomly distributed than $\mathrm{Cu}$ and $\mathrm{Pd}$ based on the images presented in Figure $4 a$, a frequency distribution analysis reveals the Pearson's coefficients of $\mathrm{Cu}(\mu=0.10)$ and $\mathrm{Pd}(\mu=0.08)$, clearly indicating a more random distribution than 
for $\operatorname{Ir}(\mu=0.41)$ and $\operatorname{Pt}(\mu=0.35)$. This is consistent with the one-dimensional concentration profile along the direction marked by the black arrow in Figure 4a, for a cylindrical region of interest of $10 \times 10 \times 50 \mathrm{~nm}^{3}$ as shown in Figure 4c, clearly indicating anti-correlated fluctuation between Pt and Au with a wavelength of $9 \pm 1 \mathrm{~nm}$. Au content varies from $12 \pm 7$ at.\%, while Pt varies between $22 \pm 7$ at. $\%$.
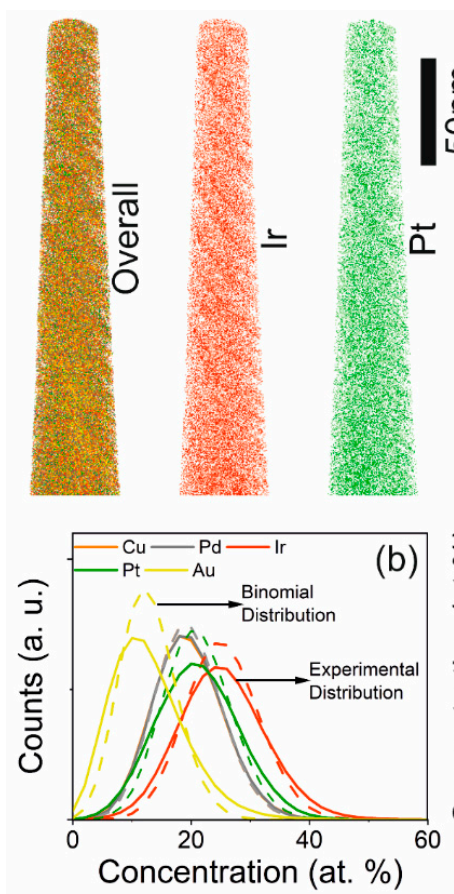
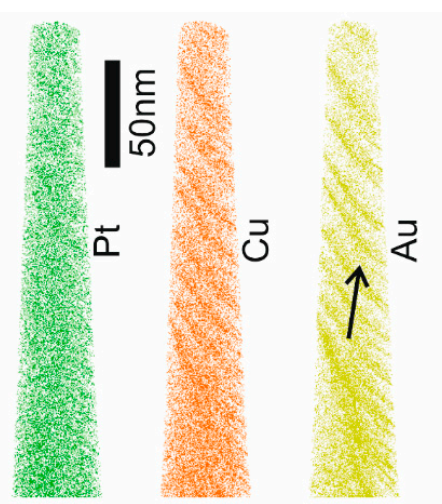

(a)

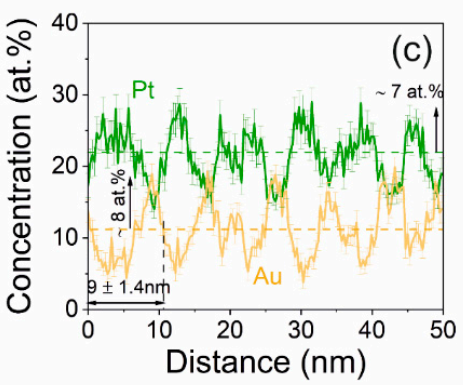

Figure 4. (a) A depiction of the overall elemental distribution as well as individual elemental distribution of $\mathrm{Pt}_{22} \mathrm{Ir}_{23} \mathrm{Cu}_{18} \mathrm{Au}_{18} \mathrm{Pd}_{19}$ deposited at $520{ }^{\circ} \mathrm{C}$ substrate temperature, via atom probe tomography. (b) Frequency distribution analysis of the respective constituting elements. (c) One-dimensional concentration profile along the direction highlighted in (a), depicting the chemical modulation of $\mathrm{Au}$ and Pt.

The phase formation observed for both $\mathrm{Pt}_{22} \mathrm{Ir}_{23} \mathrm{Cu}_{20} \mathrm{Au}_{17} \mathrm{Ag}_{18}$ and $\mathrm{Pt}_{22} \mathrm{Ir}_{23} \mathrm{Cu}_{18} \mathrm{Au}_{18} \mathrm{Pd}_{19}$ thin films deposited at $520{ }^{\circ} \mathrm{C}$ clearly contradicts the predictions based on above-discussed requirements for the formation of single-phase HEA: $\mathrm{Pt}_{22} \mathrm{Ir}_{23} \mathrm{Cu}_{20} \mathrm{Au}_{17} \mathrm{Ag}_{18}$ forms two fcc phases, while $\mathrm{Pt}_{22} \mathrm{Ir}_{23} \mathrm{Cu}_{18} \mathrm{Au}_{18} \mathrm{Pd}_{19}$ forms a metastable fcc phase with chemical modulation at the $\mathrm{nm}$ scale. At a growth temperature of $800{ }^{\circ} \mathrm{C}$, the onset of the formation of a second phase was observed by XRD for $\mathrm{Pt}_{22} \mathrm{Ir}_{23} \mathrm{Cu}_{18} \mathrm{Au}_{18} \mathrm{Pd}_{19}$ thin films. In an effort to rationalize it, the disparity between the measured and predicted phase formation serves as the motivation to investigate the effect of kinetics on the phase formation during sputtering of $\operatorname{PtIrCuAuX}(X=\mathrm{Ag}$, Pd) thin films. Specifically, the magnitude of the activation energy barrier for surface diffusion of the individual species and the associated bond strength trends are investigated.

Average ICOHP values per bond, directly correlated with the (not inherently quantifiable) bond strength, are calculated for the heteroatomic interactions of $\mathrm{X}(\mathrm{X}=\mathrm{Ag}, \mathrm{Pd})$ with $\mathrm{Pt}, \mathrm{Ir}, \mathrm{Cu}, \mathrm{Au}$ and the homoatomic $\mathrm{X}-\mathrm{X}$ interaction, as shown in Figure 5. In general, interactions of a given atom with atoms in its first coordination shell (CS) and its second CS experience an average shift of $25 \%$ and $37 \%$, respectively, of the average ICOHP per bond towards more positive values, and thus weaker bonds, upon substitution of Pd with Ag. The average ICOHP per bond for interactions with atoms in the first CS is thus strongly influenced by the substitution of Pd with $\mathrm{Ag}$, while being much less numerically affected by the substitution for interactions with atoms in the second CS; while the relative shift (37\%) is higher, the absolute values of the average ICOHP in the second CS are lower by an order of magnitude, leading to only marginal absolute differences. With an average relative shift of 
$<20 \%$ and comparable absolute values to those in the second CS, there is no quantifiable impact on the ICOHP values for interactions with atoms in the third CS as a result of the substitution. Thus, this type of interaction is not shown. Recalling that the ICOHP value is an indirect but qualitatively accurate descriptor for the bond strength, we summarize that the average strength of bonds formed between $\mathrm{Ag}$ and all other constituting elements is significantly weaker than that of bonds formed between $\mathrm{Pd}$ and other elements. The implications thereof for surface diffusion are discussed next.

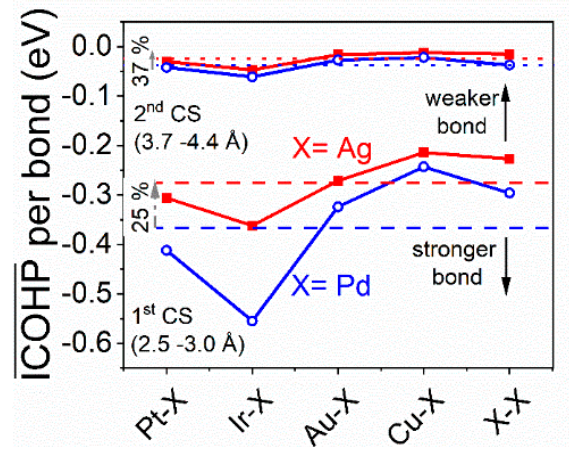

Figure 5. Integrated crystal orbital Hamilton population (ICOHP) per bond for binary combinations of $X(X=A g, P d)$ with $\mathrm{Au}, \mathrm{Cu}, \mathrm{Ir}, \mathrm{Pt}$ and $\mathrm{X}$ itself in a near-equiatomic PtIrCuAuX $(X=\mathrm{Ag}, \mathrm{Pd})$ system. CS signifies the coordination shell and the dashed lines depict the average ICOHP per bond across all interactions for the respective systems.

The activation energy barrier for surface diffusion of all the five constituting elements was calculated for both equiatomic PtIrCuAuAg and PtIrCuAuPd. These configurations closely mimic the experimental compositions. Each element is moved to its neighboring vacancy site in the (111) surface plane in $<110>$ direction. Figure 6 shows the difference between the lowest and highest energies during this process for each element in the discussed equiatomic composition, a comparison of the activation energy barriers for surface diffusion of equiatomic PtIrCuAuAg and PtIrCuAuPd is hence, illustrated. It is evident that substituting Pd with Ag causes a 35\% decrease in the average activation energy barrier for surface diffusion, corresponding to a higher mobility of elements in PtIrCuAuAg and in line with the decreased bond strengths. Although these material systems possess identical configurational entropies, the higher activation energy barriers lead to the formation of a kinetically limited single metastable phase in $\mathrm{Pt}_{22} \mathrm{Ir}_{23} \mathrm{Cu}_{18} \mathrm{Au}_{18} \mathrm{Pd}_{19}$ thin films, compared to the $35 \%$ lower average activation energy barriers enabling the formation of two fcc phases in $\mathrm{Pt}_{22} \mathrm{Ir}_{23} \mathrm{Cu}_{20} \mathrm{Au}_{17} \mathrm{Ag}_{18}$ thin films. Hence, it is now evident that the phase formation in $\operatorname{PtIrCuAuX}(X=\mathrm{Ag}, \mathrm{Pd})$ appears to be governed by a complex interplay between energetics and kinetic considerations and cannot be predicted based on the above-discussed criteria for the formation of single-phase HEAs.

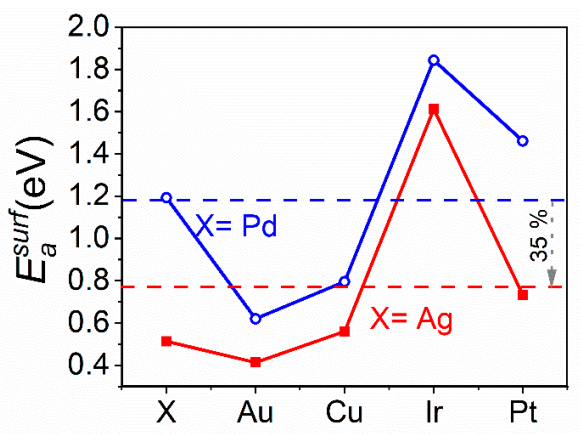

Figure 6. Activation energy barrier for surface diffusion $\left(E_{a}^{\text {surf }}\right)$, obtained via ab initio calculations for $\mathrm{Ag}, \mathrm{Au}, \mathrm{Cu}, \mathrm{Ir}, \mathrm{Pd}$ and Pt on the (111) surface in $<110>$ direction of the equiatomic PtIrCuAuX $(\mathrm{X}=\mathrm{Ag}$, $\mathrm{Pd})$ material system. The dashed line depicts the average activation energy barrier for the respective material systems. 


\section{Conclusions}

The phase formation of PtIrCuAuX (X = Ag, Pd) thin films was studied on various length scales. Both compositions fulfill the criteria for the formation for single-phase high entropy alloys, namely $12 \mathrm{~J} \cdot \mathrm{K}^{-1} \cdot \mathrm{mol}^{-1} \leq$ configurational entropy $\leq 17.5 \mathrm{~J} \cdot \mathrm{K}^{-1} \mathrm{~mol}^{-1},-10 \mathrm{~kJ} \cdot \mathrm{mol}^{-1} \leq$ enthalpy of mixing $\leq 5 \mathrm{~kJ} \cdot \mathrm{mol}^{-1}$ and atomic size difference $\leq 5 \%$. While near-equiatomic $\mathrm{Pt}_{22} \mathrm{Ir}_{23} \mathrm{Cu}_{18} \mathrm{Au}_{18} \mathrm{Pd}_{19}$ thin films, based on XRD, crystallize in a single fcc phase, APT studies revealed anti-correlated, local chemical modulations of $\mathrm{Au}$ and $\mathrm{Pt}$ with $12 \pm 7$ and $22 \pm 7$ at.\%, respectively, and a wavelength of $9 \pm 1 \mathrm{~nm}$.

For near-equiatomic $\mathrm{Pt}_{22} \mathrm{Ir}_{23} \mathrm{Cu}_{20} \mathrm{Au}_{17} \mathrm{Ag}_{18}$ thin films, the formation of two fcc phases was observed by XRD. APT revealed that one phase was rich in $\mathrm{Au}$ and $\mathrm{Ag}$, while the other one was rich in $\mathrm{Pt}$ and $\mathrm{Cu}$. Furthermore, the solubility of both $\mathrm{Au}$ and $\mathrm{Ag}$ in the $\mathrm{Pt}-\mathrm{Cu}$ - rich region was observed to be $\geq 5$ and $\geq 3$ at. $\%$, respectively, while the solubility of $\mathrm{Pt}$ and $\mathrm{Cu}$ in the $\mathrm{Au}-\mathrm{Ag}$ rich region is $\geq 10$ at.\%. These observations are clearly inconsistent with the HEA design criteria discussed above.

In an attempt to rationalize the disparity between experimentally obtained data and the phase formation predictions, the bond strengths and the activation energy barriers for surface diffusion of each constituting element were calculated. The effect of substitution of Pd by Ag on the bond strength was probed via the average integrated crystal orbital Hamiltonian population per bond. Bond strength for heteroatomic interactions of $X-Y(X=A g, P d, Y=P t, I r, C u, A u)$ decreases on average by $25 \%$ in the first coordination shell. This decrease in bond strength causes a concomitant decrease in the average surface diffusion activation energy barrier by $35 \%$. These observations can aid in rationalizing the phase formation in these material systems, as the larger energetic barriers for $\mathrm{Pt}_{22} \mathrm{Ir}_{23} \mathrm{Cu}_{18} \mathrm{Au}_{18} \mathrm{Pd}_{19}$ enable the formation of a single, metastable phase at a substrate temperature of $520^{\circ} \mathrm{C}$ due to kinetically limited growth. In contrast, the barriers for $\mathrm{Pt}_{22} \mathrm{Ir}_{23} \mathrm{Cu}_{20} \mathrm{Au}_{17} \mathrm{Ag}_{18}$, lower by $35 \%$ on average, result in sufficient mobility to initiate phase separation at the same substrate temperature. It is hence evident that the phase formation of physical vapor deposited PtIrCuAuX (X $=\mathrm{Ag}, \mathrm{Pd})$ thin films is defined by a complex interplay of energetics and kinetic limitations and not by the configurational entropy.

Author Contributions: A.S. and J.M.S. conceptualized the research question and developed the research framework. Thin film synthesis and experimental analysis (XRD, APT) was performed by A.S. and H.S. Ab initio calculations were performed by A.S. and D.B. according to the methodological recipes previously established by D.M. (activation energies) and D.B. (bonding analysis) A.S. and D.B. carried out the data interpretation, validated in discussions with all authors. The first draft of the manuscript was written by A.S. with assistance from D.B. and subsequent editing by all authors. J.M.S. supervised the project. All authors have contributed to the final version of the manuscript and agreed to the published form.

Funding: The authors most gratefully acknowledge funding through DFG within the priority program SPP 2006 CCA-HEA and the computing resources provided by the IT Center of RWTH Aachen University, granted by the Jülich-Aachen Research Alliance's High-Performance Computing section (JARA-HPC) under the project JARA0131.

Conflicts of Interest: The authors declare no conflict of interest.

\section{References}

1. Darling, A.S. Iridium Platinum Alloys. Platin. Met. Rev. 1960, 4, 18.

2. Darling, A.S. Gold Platinum Alloys. Platin. Met. Rev. 1962, 6, 106.

3. Merker, J.; Lupton, D.; Toepfer, M.; Knake, H. High Temperature Mechanical Properties of the Platinum Group Metals. Platin. Met. Rev. 2001, 45, 74-82.

4. Yuan, H.; Yoo, W.-J.; Miyamura, H.; Kobayashi, S. A Cooperative Catalytic System of Platinum/Iridium Alloyed Nanoclusters and a Dimeric Catechol Derivative: An Efficient Synthesis of Quinazolines Through a Sequential Aerobic Oxidative Process. Adv. Synth. Catal. 2012, 354, 2899-2904. [CrossRef]

5. Yuan, H.; Yoo, W.-J.; Miyamura, H.; Kobayashi, S. Discovery of a Metalloenzyme-like Cooperative Catalytic System of Metal Nanoclusters and Catechol Derivatives for the Aerobic Oxidation of Amines. J. Am. Chem. Soc. 2012, 134, 13970-13973. [CrossRef] [PubMed]

6. Ganske, G.; Slavcheva, E.; van Ooyen, A.; Mokwa, W.; Schnakenberg, U. Sputtered platinum-iridium layers as electrode material for functional electrostimulation. Thin Solid Films 2011, 519, 3965-3970. [CrossRef] 
7. Ioroi, T.; Yasuda, K. Platinum-Iridium Alloys as Oxygen Reduction Electrocatalysts for Polymer Electrolyte Fuel Cells. J. Electrochem. Soc. 2005, 152, A1917-A1924. [CrossRef]

8. Muhammad, N.; Whitehead, D.; Boor, A.; Oppenlander, W.; Liu, Z.; Li, L. Picosecond laser micromachining of nitinol and platinum-iridium alloy for coronary stent applications. Appl. Phys. A 2012, 106, 607-617. [CrossRef]

9. Kathuria, Y.P. An overview on laser microfabrication of bicompatible metallic stent for medical therapy. In Proceedings of the Laser-Assisted Micro- and Nanotechnologies, St. Petersburg, Russian, 29 June-3 July 2003.

10. Bobzin, K.; Bagcivan, N.; Brögelmann, T.; Münstermann, T. Correlation between Chemical Glass Components and the Glass Sticking on Sputtered PtIr Physical Vapour Deposition Coatings for Precision Blank Moulding. Mater. Sci. Appl. 2014, 5, 316-329. [CrossRef]

11. Bobzin, K.; Bagcivan, N.; Ewering, M.; Brugnara, R.H.; Münstermann, T. Influence of interlayer thickness of a thin noble metal MSIP-PVD coating on compound and system properties for glass lens moulding. Prod. Eng. 2012, 6, 311-318. [CrossRef]

12. Klocke, F.; Dambon, O.; Georgiadis, K. Comparison of Nitride and Noble Metal Coatings for Precision Glass Molding Tools. Key Eng. Mater. 2010, 438, 9-16. [CrossRef]

13. Klocke, F.; Dambon, O.; Rohwerder, M.; Bernhardt, F.; Friedrichs, M.; Merzlikin, S.V. Model of coating wear degradation in precision glass molding. Int. J. Adv. Manuf. Technol. 2016, 87, 43-49. [CrossRef]

14. Sohn, S.; Liu, Y.; Liu, J.; Gong, P.; Prades-Rodel, S.; Blatter, A.; Scanley, B.E.; Broadbridge, C.C.; Schroers, J. Noble metal high entropy alloys. Scr. Mater. 2017, 126, 29-32. [CrossRef]

15. Murty, B.S.; Yeh, J.W.; Ranganathan, S.; Bhattacharjee, P.P. High-Entropy Alloys, 2nd ed.; Murty, B.S., Yeh, J.W., Ranganathan, S., Bhattacharjee, P.P., Eds.; Elsevier: New York, NY, USA, 2019; pp. 31-50.

16. Miracle, D.B.; Senkov, O.N. A critical review of high entropy alloys and related concepts. Acta Mater. 2017, 122, 448-511. [CrossRef]

17. Yeh, J.W.; Chen, S.K.; Lin, S.J.; Gan, J.-Y.; Chin, T.-S.; Shun, T.-T.; Tsau, C.-H.; Chang, S.-Y. Nanostructured High-Entropy Alloys with Multiple Principal Elements: Novel Alloy Design Concepts and Outcomes. Adv. Eng. Mater. 2004, 6, 299-303. [CrossRef]

18. Zhang, Y.; Zhou, Y.J.; Lin, J.P.; Chen, G.L.; Liaw, P.K. Solid-Solution Phase Formation Rules for Multi-component Alloys. Adv. Eng. Mater. 2008, 10, 534-538. [CrossRef]

19. Troparevsky, M.C.; Morris, J.R.; Daene, M.; Wang, Y.; Lupini, A.R.; Stocks, G. Malcolm Beyond Atomic Sizes and Hume-Rothery Rules: Understanding and Predicting High-Entropy Alloys. JOM 2015, 67, 2350-2363. [CrossRef]

20. Troparevsky, M.C.; Morris, J.R.; Kent, P.R.C.; Lupini, A.R.; Stocks, G.M. Criteria for Predicting the Formation of Single-Phase High-Entropy Alloys. Phys. Rev. X 2015, 5, 011041. [CrossRef]

21. King, D.J.M.; Middleburgh, S.C.; McGregor, A.G.; Cortie, M.B. Predicting the formation and stability of single phase high-entropy alloys. Acta Mater. 2016, 104, 172-179. [CrossRef]

22. Chattopadhyay, C.; Prasad, A.; Murty, B.S. Phase prediction in high entropy alloys-A kinetic approach. Acta Mater. 2018, 153, 214-225. [CrossRef]

23. Saksena, A.; Chien, Y.-C.; Chang, K.; Kümmerl, P.; Hans, M.; Völker, B.; Schneider, J.M. Metastable phase formation of Pt-X (X=Ir, Au) thin films. Sci. Rep. 2018, 8, 1-10. [CrossRef] [PubMed]

24. Marshal, A.; Pradeep, K.G.; Music, D.; Zaefferer, S.; De, P.S.; Schneider, J. Michael Combinatorial synthesis of high entropy alloys: Introduction of a novel, single phase, body-centered-cubic FeMnCoCrAl solid solution. J. Alloys Compd. 2017, 691, 683-689. [CrossRef]

25. Barbee, T.W.; Holmes, W.H.; Keith, D.L.; Pyzyna Mitchell, K.; Ilonca, G. Synthesis of amorphous niobium-nickel alloys by vapor quenching. Thin Solid Films 1977, 45, 591-599. [CrossRef]

26. Goldstein, J.I.; Newbury, D.E.; Joy, D.C.; Lyman, C.E.; Echlin, P.; Lifshin, E.; Sawyer, L.; Michael, J.R. Quantitative X-Ray analysis: The basics. In Scanning Electron Microscopy and X-Ray Microanalysis, 3rd ed.; Goldstein, J.I., Newbury, D.E., Joy, D.C., Lyman, C.E., Echlin, P., Lifshin, E., Sawyer, L., Michael, J.R., Eds.; Springer US: Boston, MA, USA, 2003; pp. 391-451.

27. Kresse, G.; Hafner, J. Ab initio molecular dynamics for open-shell transition metals. Phys. Rev. B 1993, 48, 13115-13118. [CrossRef] [PubMed]

28. Kresse, G.; Hafner, J. Ab initio molecular-dynamics simulation of the liquid-metal-amorphous-semiconductor transition in germanium. Phys. Rev. B 1994, 49, 14251-14269. [CrossRef]

29. Blöchl, P.E. Projector augmented-wave method. Phys. Rev. B 1994, 50, 17953-17979. [CrossRef] 
30. Perdew, J.P.; Burke, K.; Ernzerhof, M. Generalized Gradient Approximation Made Simple. Phys. Rev. Lett. 1996, 77, 3865-3868. [CrossRef]

31. Kresse, G.; Joubert, D. From ultrasoft pseudopotentials to the projector augmented-wave method. Phys. Rev. B 1999, 59, 1758-1775. [CrossRef]

32. Blöchl, P.E.; Jepsen, O.; Andersen, O.K. Improved tetrahedron method for Brillouin-zone integrations. Phys. Rev. B 1994, 49, 16223-16233. [CrossRef]

33. Monkhorst, H.J.; Pack, J.D. Special points for Brillouin-zone integrations. Phys. Rev. B 1976, 13, 5188-5192. [CrossRef]

34. Chang, K.; to Baben, M.; Music, D.; Lange, D.; Bolvardi, H.; Schneider, J.M. Estimation of the activation energy for surface diffusion during metastable phase formation. Acta Mater. 2015, 98, 135-140. [CrossRef]

35. Cowley, J.M. X-Ray Measurement of Order in Single Crystals of Cu3Au. J. Appl. Phys. 1950, 21, 24-30. [CrossRef]

36. Birch, F. Finite Elastic Strain of Cubic Crystals. Phys. Rev. 1947, 71, 809-824. [CrossRef]

37. Chang, K.; Music, D.; To Baben, M.; Lange, D.; Bolvardi, H.; Schneider, J.M. Modeling of metastable phase formation diagrams for sputtered thin films. Sci. Technol. Adv. Mater. 2016, 17, 210-219. [CrossRef] [PubMed]

38. Liu, S.; Chang, K.; Mráz, S.; Chen, X.; Hans, M.; Music, D.; Primetzhofer, D.; Schneider, J.M. Modeling of metastable phase formation for sputtered Ti1-xAlxN thin films. Acta Mater. 2019, 165, 615-625. [CrossRef]

39. Dronskowski, R.; Bloechl, P.E. Crystal orbital Hamilton populations (COHP): Energy-resolved visualization of chemical bonding in solids based on density-functional calculations. J. Phys. Chem. 1993, 97, 8617-8624. [CrossRef]

40. Deringer, V.L.; Tchougréeff, A.L.; Dronskowski, R. Crystal Orbital Hamilton Population (COHP) Analysis As Projected from Plane-Wave Basis Sets. J. Phys. Chem. A 2011, 115, 5461-5466. [CrossRef]

41. Maintz, S.; Deringer, V.L.; Tchougréeff, A.L.; Andrei, L.; Dronskowski, R. Analytic projection from plane-wave and PAW wavefunctions and application to chemical-bonding analysis in solids. J. Comput. Chem. 2013, 34, 2557-2567. [CrossRef]

42. Maintz, S.; Deringer, V.L.; Tchougréeff, A.L.; Andrei, L.; Dronskowski, R. LOBSTER: A tool to extract chemical bonding from plane-wave based DFT. J. Comput. Chem. 2016, 37, 1030-1035. [CrossRef]

43. Landrum, G.A.; Dronskowski, R. The Orbital Origins of Magnetism: From Atoms to Molecules to Ferromagnetic Alloys. Angew. Chem. Int. Ed. 2000, 39, 1560-1585. [CrossRef]

44. Amano, S.; Bogdanovski, D.; Yamane, H.; Terauchi, M.; Dronskowski, R. $\varepsilon$-TiO, a Novel Stable Polymorph of Titanium Monoxide. Angew. Chem. Int. Ed. 2016, 55, 1652-1657. [CrossRef] [PubMed]

45. Van Santen, R.A.; Tranca, I. How molecular is the chemisorptive bond? Phys. Chem. 2016, 18, 20868-20894. [CrossRef] [PubMed]

46. Moody, M.P.; Stephenson, L.T.; Ceguerra, A.V.; Ringer, S.P. Quantitative binomial distribution analyses of nanoscale like-solute atom clustering and segregation in atom probe tomography data. Microsc. Res. Tech. 2008, 71, 542-550. [CrossRef] [PubMed]

(C) 2020 by the authors. Licensee MDPI, Basel, Switzerland. This article is an open access article distributed under the terms and conditions of the Creative Commons Attribution (CC BY) license (http://creativecommons.org/licenses/by/4.0/). 